\title{
DIE PLEK VAN SANG EN MUSIEK IN DIE PROTESTANTSE EREDIENS. 1)
}

1. INLEIDENDE OPMERKINGS :

(a) In die behandeling van bostaande onderwerp. bevind ons ons op die gebied van die Praktiese Teologie.

Die Praktiese Teologie het ' $n$ merkwaardige tweeledige bestaan, Dit bestaan aan-die-een-kant sinvol as wetenskaplike besinning en spreke oor die ,erediens"; dit bestaan aan-die-ander-kant óók sinvol in die daad-werklike uitvoering van hierdie wete, van hierdie „blijde wetenschap." Dit is wetenskap van die kerklike lewensverrigtinge, van die kerklike handeling, van die kerklike doen in die erediens; dit is tegelykertyd ook onafskeidbaar hiermee verbonde, hierdie lewensverrigtinge, hierdie dade van diens self.

Praktiese Teologie is logos, maar tegelykertyd óók praxis -- dit is praktiese logos, daad-werklike woord. Dit is Teologie wat uit die Erediens voortkom en wat uiteindelik weer daad van Erediens word. Die één (die Teologie) en die ánder (die Praktyk) kan nooit sonder mekaar bestaan of los van mekaar staan nie. Die Praktiese Teologie sonder die daad-werklike voltrekking in die praktyk, sal leë gepraat wees ..... die daadwerklike uitvoering van die lewensverrigtinge sal aan-die-ander-kant weer, sonder die teologiese denkdiens daaragter, 'n gedagtelose, formalistiese doen wees. Die Teologie vind haar sin

1) Wat hier afgedruk word, is 'n lesing gehou voor die Kongres van die "Raad van Kerkmusiek" van die Nederduitsch Hervormde Kerk, te Krugersdorp. Hierdeur is die vorm (bv. die spreektrant en die spaarsaamheid van aanhalings uit ander werke) tot 'n groot mate bepaal. Ons hoop dat dit ook in huidige vorm tog ook nuttig mag wees. 
daarin dat dit uiteindelik daad van erediens word; die Erediens is eers sinvol as daaragter die denkdiens van die teologie staan.

Laat ons in hierdie verband op twee voorbeelde heenwys.

(i) In die erediens sing en spreek die gemeente haar geloofsbelydenis uit grwoonlik in die vorm van die Apostolicum. Hiedie geloofsbelydenis neem ' $n$ betreklik kort tydsruimte in die geheel van die erediens in beslag. Maar nou spreek die gemeente nie die beslissing en belydenis van haar hart in willekeurige, ondeurdagte woorde uit nie. Agter hierdie skynbaar-skraal woorde van belydenis lê eeue van wetenskaplike worsteling met gedagtes, woorde en dwaalleringe om so-denkende en sodoende hierdie belydenis suiwer te sê en af te grens teen dit wat dit nie is nie, en nie behoort te wees nie.

Ons het dus in die Geloofsbelydenis 'n teologies-weldeurdagte weldeurworstelde element van die daadwerkelike ereddiens. Dit is goed dat ons ook só sal besin en sal worstel om die duidelike verstaan van die ander elemente in die erediens, ook van die eltemente van Sang en Musiek.

(ii) Die tweede voorbeeld waarop ons wil heenwys om die noue verbondenheid van die erediens in haar daadwerklikheid met die denkdiens daaragter uit te druk, is die volgende:-

Aan byna elke wetenskap is daar 'n stuk metafis:ka vasgeheg. Aanvanklik gaan hulle uit van die feitelike gegewens, maar uiteindelik word die gebied van die feitelikheid verlaat en word daar oor die grondslae, hypotheses, perspektiewe ens. van die bepaalde vak gespreek en altyd op so'n wyse dat dit van min-of-meer van bespiegelende, kontemplatiewe of spekulatiewe aard is - d.w.s. abstrak (ge$a b$-straheer van die feitelike gegewens), metafisies. Maar die egreformatoriese teologie ken geen metafisika nie. Dit ken geen metafisika nie, omdat sy weet dat sy met geen griekse physis te doen het nie, maar met bybelse werklikheid van ktisis . . . en die vervullng van die ware werklikheid van die ktisis is nie om te spekuleer nie, maar om God te dien. ${ }^{2}$ ) En in hierdie erediens word die physis deurbreek - hulle wat bv. fisies geen familie van mekaar is nie, word in hierdie diens ,"broeders en susters" van mekaar.

Ons kan dit ook so stel: Nadat die Teologie in die Universitêre klaskamer wetenskaplik gespreek en besin het, gaan dit in die ruimte van die kerkgebou preek en sing. Nadat die Teologie verklaar en begryp het, gaan sy nie abstrak bespiegel nie (ook nie in die Prolegomena tot elke vak of in die Teologiese Ensiklopedie nie), maar word sy tot handeling tot "existensiele kommunikasie," tot "communio

2) Vgl. o.a. v.d. Leeuw, Inleiding, 2, blz. 95 v.v. 
sanctorium" in al die wisselende bestaansvorme van Nagmaal (communio), Doop, Prediking, ens. $\left.{ }^{3}\right)$.

Ook hieruit blyk die twee-ledige en tegelykertyd eenvoudige karakter van Praxis en logos in die Teologie, en blyk verder ook die dringendheid van grondige teologiese besinning op hierdie gebied. Alleen wanneer ons grondig besin het, sal ons "nie uit gewoonte of bygelowigheid" in die erediens sit nie, maar sal ons die ware sin van van die woord kan méé-leef en méé-doen tot eer van God.

(b) Nadat ons in die eerste opmerking die verband tussen die Kerklike praxis en logos probeer aantoon het, moet ons hier nog 'n tweede opmerking maak: Dit is geensins so dat die logos (die Teologie) die grond is van die praxis (die Kerk en bygevolg ook die Erediens) nie. Die Kerk was eerste daarná eers het ons Teologie gekom. Die Teologie het alleen ' $n$ dienende en korrektiewe funksie. Die Kerk is nie daar om die Teologie te dien nie, maar omgekeerd: Die Teologie om die Kerk te dien; en beide, Kerk en Teologie, om God te dien.

Dit is oor sekere elemente van hierdie diens waaroor ons hier wil besin.

(c) Die opmerksame leser sal alreeds gemerk het dat ons hier die woord ..Erediens" in byna on-kritiese sin gebruik. Wel is ons bewus van die problematiek rondom hierdie woorde "liturgie" en „erediens" in die diskussie oor hierdie sake in die teologie van die Vasteland van Europa. Gelukkig kan ons in Suid-Afrika nog in hierdie opsig onproblematies wees en onder ,erediens" verstaan: Die diens wat in die ruimte van die Kerkgebou plaasvind tot diens en eer van die Here God.

(d) Nog 'n laaste inleidende opmerking: Dit gaan hier om die Plek van Sang en Musiek in die Protestantse Erediens. Dit gaan dus nie om 'n historiese oorsig of om die wesensbepaling van hierdie belangrike elemente in die erediens nie, maar dit gaan om 'n verhouding. Ons sal bygevolg hierdie belangrike relatiwiteit, hierdie feit dat dit hier om 'n relasie van gebeurtenisse binne die geheel van die erediens gaan, nie uit die oog moet verloor nie.

\section{Fragmentariese Voorbeelde uit die Oue Testament.}

Ons het dus geensins tot doel om hier te spreek oor die groei van die sang en musiek in die christelike erediens vanuit die oud-testamentiese vorme, deur die oer-en oud-christelike wyses en vorme van inrigting heen, tot vandag-toe nie. Laat ons egter die volgende aanstip: : Die oudste gedeeltes van die Bybel is vol van sang en musiek en sage waarvan ons die oudheid alleen maar kan vermoed en

3) Cf. v.d. Leeuw, Inleiding ${ }^{2}$, blz. 256. 
raai, maar nooit seker sal weet nie. Alreeds in Genesis 4 lees ons van die "Lied van Lameg," die lied van swaard en wraak. Dit wat die grootste lewenswaarde vir Lameg is, sy krag wat tegelykertyd sy hele lewe is, dit kan hy nie meer binne in hom hou nie, kan hy ook nie rustig vertel en sê, maar kan hy alleen maar uit-sing. Hy sing dit uit teenoor hulle wat 'n onverbreekbare bestanddeel van sy bestaan is, sy twee vroue Ada en Silla . . . teenoor hulle wat hy liefhet.

En hier tree alreeds een van die wesenskenmerke van sang en musiek na vore, nl. dat dit een van die beslissende magte in ons bestaan is. D.i. nl. dié uitdrukkingswyse wanneer iets ons in die diepste van ons bestaan aangryp en ons nie anders kan as om dit aan onsself en aan ander mee te deel nie. Dit is geen wonder dat die eerste christelike belydenisse (die enigste troos en lewenswaarheid vir hulle wat dit moeilik gehad het) nie uitgespreek is nie, maar uitgesing is.

Maar as Lameg alleen maar die musiek van sy eie stem gehad het, sy seun Jubal het blykbaar hierdie musikale gawe van sy vader oorgeërf en dit instrumentaal uitgebrei. Daarom word hy in Genesis 4 vers 21 , die vader van almal wat op die siters en fluite speel" genoem.

Eintlik is al hierdie oeroue gedeeltes van die Oue Testament (netsoos ook die vroegste woorde van ander ou volkere en kulture) vol drinkliedere, liefdesliedere, spotliedere en oorwinningsliedere. By almal is daar ' $n$ religieuse klank hoorbaar en by almal het die lied en die musiek dié funksie dat dit uitdrukking gee aan die diepste vreugde, wraak en ander ontroeringe van diegene wat sing en speel. Tereg is gesê: Die mens sing en maak musiek voordat hy nog behoorlik kan praat.

Maar laat ons nog één van hierdie oudste liedere van die Bybel noem, nl. die Skelfseelied van Exodus 15:

„Toe het Moses en die kinders van Israel hierdie lied tot eer van die Here gesing; en dit is wat hulle gesing het: Ek wil sing tot eer van die Here want $\mathrm{Hy}$ is hoog verhewe. Die perd en die ruiter het $\mathrm{Hy}$ in die see gewerp. Die Here is my krag en my psalm en $\mathrm{Hy}$ het my tot heil geword. Hy is my God. Hom sal ek roem; die God van my vader; ek sal Hom verhef . . . . .

Hierdie mense word nie soos Lameg deur hulle eie krag bekoor en oorweldig, om dit daarna uit te sing nie, maar hulle word deur die geweldige krag en groot goedheid van God oormeester en hierdie krag en heil is só ingrypend, só lewensbeslissend dat hulle nie anders kan as om dit uit te jubel en te besing nie. Die Skelfseelied sê : "Die Here is my krag en my psalm." Ons kan dit in hierdie verband só stel : „omdat Hy my krag is, daarom moet ek Hom psalmsing.

Hierdie psalmgesang is antwoord van die mens op die groot dade van God. Dit is Hy wat hulle gered het, wat die ruiter en perd van 
Farao in die see gewerp het. Daarom hierdie onweerstaanbare, hierdie eksistensiële en tegelykertyd tog blye antwoord.

'n Ander wesenlike kenmerk wat hierdie lied na vore tree, is die feit dat die hele volk gesamentlik daaraan deelneem. 'n Groep mense, bv. 'n gemeente, kan moeilik almal saam spreek sonder in 'n ongeorganiseerdheid, in die onordelikheid van die massa te verval . . . . . maar hulle kan en moet wel saam sing.

Die insigte wat ons hier ingewin het, is die volgende:

1. Die lied is hier (in teenstelling met die lied van Lameg) volkome Gods-dienstig; dit is inbetrek in die ligkring van die diens en eer van God en vervul 'n wesenlike funksie in hierdie eerste, nog ruwe, feestelike, spontane „erediens".

2. Die lied toon sig verder as die eksistensiële antwoord van die mens op die groot dade van die guns en die genade van God.

3. Dit is veral die gepaste antwoordsvorm van die volksvergadering, van die groot groep, van die oudtestamentiese gemeente.

Maar nou word hierdie lied wat eenkeer spontaan en vreugdevol by hierdie eerste feesgeleentheid gesing is, weer-en-weer gesing en in die gereëlde erediens inbetrek. En ook nuwe liedere word gedig en gesing binne die kring van die kultus, van die ou-testamentiese erediens, Psalm 89 vers 1 sê bv.: .,Sing tot eer van die Here 'n nuwe lied, want Hy het wonders gedoen ....." 'n Nuwe lied word gedig en gesing omdat die ou liedere nie meer hierdie nuwe vreugde, lof of klag kan uitdruk nie.

Die Psalms veral is vol van hierdie liedere wat bestem is vir die vaste, gereëlde erediens. Hulle pas veral in by die "feestelike jaar" van Israel. Dit behoort wesenlik by die gebeurtenisse van heil dat hulle onthou en vertel, maar veral dat hulle feestelik gesing en besing sal word. Maar nou word die hoofmomente van hierdie "feestelike jaar" nie deur mense bepaal nie, maar deur Gods dade, deur Sy goedheid en trou; en die liedere skik hulle na hierdie vorme en hierdie inhoud.

Dit is veral by hierdie liedere dat ons sekere aanwysings kry i.v.m. die begeleidende musiek. Hieroor het ons egter baie min gegewens.

Wat egter van beslissende belang is, is die feit dat God die lied en musiek as antwoordsvorm van die mens (as dit reg gebeur), goed vind, dat $\mathrm{Hy}$ wil dat dit so sal wees en so sal gebeur. Hiervan hang alles af. Dit gaan in die eerste instansie nie om die eksistensiële karakter van sang en musiek as menslike lewens- en antwoordvorm nie; dit gaan ook nie primêr om die skoonheid daarvan nie. Dit gaan primêr daarom dat dit ware lofprysing, jubelsang, klagte of gebed voor die aangesig van God is, én dat $H_{y}$ dit so goed vind. Die Here God kan ook sê : „Ek haat julle feeste en het geen welgevalle aan julle feestye nie .... Verwyder van My die geraas van jou liedere! En na die geluid van jou 
harpe wil Ek nie luister nie." (Amos 5 verse 21 en 23). Die korrektheid en skoonheid van die vorm van die lied en musiek, asook die feit dat dit op die gereëlde feestyd tydig plaasvind, is nog geen waarborg dat dit welgevallig voor die aangesig van God is nie. Dit gaan daarom dat vorm en inhoud eksistensieël deurleef en klankvol tot uitdrukking gebring word, en dat $\mathrm{Hy}$, die Kenner van die harte, dit goed vind en reg.

\section{Die Nuwe Testament en die Lied.}

Kom ons by die Nuwe Testament, dan vind ons dat die Kerk 'n opdrag het om uit te voer. Sy moet hierdie opdrag uitvoer deur middel van die Prediking d.w.s. deur middel van die Woord-vorm, maar ook deur die bediening van die sakramente, dws. deur middel van die vorm van die Daad. Maar nou wil God nie hê dat die Kerk slegs éenmaal die Evangalie sal predik en die mense sal doop om hulle daarna aan hulle eie lot oorlaat nie. Hy wil dat daar 'n gemeente sal wees. $\mathrm{Hy}$ vergader deur Sy Gees rondom Sy woord vir Hom 'n gemeente om Hom te dien en eer en vrees, om in erediens bymekaar te kom. Die ander sakrament nl. die Heilige Nagmaal wys heen na die herhaaldelike, duratiewe karakter van hierdie erediens. „Want so dikwels as julle hierdie brood eet en hierdie beker drink, verkondig julle die dood van die Here totdat Hy kom." (1 Kor. 11 vers 26). Dit is dus 'n handeling wat herhaaldelik gebeur en sig uitstrek tussen Opstanding en Deder koms. Christenword is nie 'n eenmaal-afgehandelde daad nie. Telkens weer-en-weer is daar sonde, veral en gebrokenheid - maar telkens ook weer nuwe hulp en groot dade van heil van onse God en daarom telkens ook weer die oproep om 'n nuwe lied tot eer van die Here te sing. En so verskyn daar naas die gestaltes van Woord en Daad die derde gesialte nl. die Skone Klank, ${ }^{4}$ ) die van lied en musiek wat staan in die diens van die Here.

In die Oue Testament word gesê dat God troon op die lofsange van Israel. Dit wil $\mathrm{Hy}$ ook van die nuwe-testamentiese gemeente hê, nl. dat ons sy groot dade in lied en sang en met die skone klank van musiek sal herdenk en sal noem, sal prys en sal uitsing - veral die sentrale wonderdaad van Sy genade en liefde nl. die vleeswording van onse Here Jesus Christus.

„Om dit te doen is eintlik die taak van ons hele lewe" (Van der Leeuw). Binne die ruimte van die kerkgebou (d.w.s. in die erediens) is dit veral die taak van die sang en musiek. In die vervulling van hierdie taak is dit veral die blye plig van die kerkmusiek om klankvolle leiding, agtergrond en vorm aan die erediens te verleen - om onder andere ook met die ragfyn en onsigbare draad van die klank die afsonderlike ele-

5) cf. Van der Leeuw, Liturgiek 2, blz. 123 en 125. 
meniı van die erediens (br. gebed en prediking) tot één eenheid saam te weef.

Netsoos in die Oue Testament, is ook die Nuwe Testament dus vol van die klankvolle vorm van lied en musiek. Die eerste Christengemeente kom saam met blydskap. Hulle breek die brood met gejuig. Dit is die vreugde wat die Christengemzente het in die heilsdaad van God in Jesus Christus. Hierdie klankvolle vorm is in die Nuwe Testament dikwels die uitingswyse van die engele as hulle die aarde besoek, ook die uitingswyse van die heiliges voor Gods troon. ${ }^{5}$ )

Die N.T. begin met die engelsang by die geboorte van Christus .... . begin volgens Lukas alreads by die lofsang van Maria en Sagaria vóór Sy geboorte; dit sluit die lofliedere van Paulus en Silas in die gevangenis in die nagte Philippi in, en loop uit op die loflied van die Openbaring van Johannes. Hiertussen (d.w.s. tussen die nuwe-testamentiese lied en die toekoms van die Here) lê die taak van óns liedere en óns musiek in hulle huidige staat en vorm.

Die merkwaardige is dat die lied nie aan die einde van die dae ophou om te besiaan nie. Dit het eskatologiese, "hemelse" karaktertrekke en beiekenis. Ons het bv. alreeds heengewys na die lied van die heiliges voor Gods troon. Sommige van die elemente van die erediens, .profesië - hulle sal tot niet gaan; of tale - hulle sal ophou; of ken nis - dit sal tot niei gaan" (1 Kor. 13 vers 8). maar die liefde en (volgens ander gedeeltes uit die Bybel) die lofprysing van die lied sal bly bestaan.

\section{Die Plek van die Licd en Musiek in dio Erediens.}

Gesien hierdie Bybelse agtergrond, is dit nie te verwonder dat sang en kerkmusiek in die uitdrukking van die smeekgebede, klagte, dankbaarheid, jubel en lofprysing van die gemeente 'n baie belangrike rol speel nie.

Dit beklee 'n baie belangrike plek in die erediers, d.w.s. dit speel geen ondergeskikte rol nie, maar dit moet ook nooit oorheersend wees nic. Dit kan nooit oorheersend wees nie, eerstens omdat dit in diens van die Here God staan, en tweedens omdat dit in die erediens in betrekking to: die ander elemente van die erediens staan en wesenlik deel van daardie betrekking uitmaak. As musiek en sang in diens van die Here staan om die offer van lof te bring, dan kan hulle nooit self heer wees nie, maar dienaar. Daarom mozt die kerksang, maar veral ook die begeleiding, nooit daarop uit wees om kunstige en kunsmatige effekte na te streef nie. 'n Dienaar ken sy plek voor God en ook sy plek in die hele samehang wat ons erediens noem. Ruk dit sigself los uit hierdie same-

4) So-ook $v . d$. Leeuw, Handboek d. Eredienst, blz. 181. 
hang, dan ontstaan dit, waarteen Paulus herhaaldelik waarsku wanneer hy oor die erediens en gemeente praat, nl. onordelikheid. (Vgl. bv. 1 Kor. 12; 1 Kor. 11 vers 17 ens.)

'n Dienaar van die Here dien nie om oormoedig op die voorgrond te tree en te heers nie, maar dien in nederigheid. Aan-die-anderkant is ' $n$ dienaar van God geen slaaf nie, maar vryman. Ook die sang en musiek in die erediens dien nie as slawe nie, maar met waardigheid. In die verbinding en balans van hierdie nederigheid en hierdie waardigheid voor God, vind hulle hulle regmatige plek in die hele samehang van die erediens. Dit gaan in die erediens nie om die mooi of selfs religieuse stemminge nie. Dit gaan nie daarom nie, omdat dit in die erediens nie om ons eer gaan nie, nie om ons vermoë en selfs passende, stemmingsvolle effekte nie, maar om die eer en diens van God. Indien die Kerksang en Kerkmusiek weet dat hulle ' $n$ taak, 'n bediening, vervul, dat hulle daar is om God te dien, dan het hulle 'n heerlike voorreg waarvoor beide bly is.

Laat ons vir die verdere uiteensetting van ons onderwerp ' $n$ praktiese voorbeeld neem $\mathrm{nl}$. die gebruiklike inrigting van 'n erediens in ' $n$ Hervormde Gemeente hier in Suid-Afrika. Gewoonlik kry ons eers die Voorsang en daarná, in die volgende volgorde: Votum en Seëngroet, Wet en Geloofsbelydenis, Sang ná die Belydenis, Skriflesing. Tussensang, Gebed, Sang-voor-die Prediking, Prediking van die Woord. Dankgebed, Slotsang en Seënbede.

In die geloof is die gemeente daarvan bewus dat in elkeen van hierdie momente Gods Woord en mensewoord ten nouste met mekaar verbonde is, saam ineengevleg is, netsoos Jesus Christus tegelykertyd waaragtige ewige God én waaragtige regverdige mens was. Die gemeente glo en bely dat sy temidde van alle menslike swakheid, sonde en gebrokenheid tegelykertyd die liggaam van Christus is. Hierdie klanke word ook hoorbaar in haar erediens.

Laat ons die volgende voorbeelde neem: (a) Votum en Seëngroet. Dit is geen towerformule wat die mens alleen maar deurgee nie. Dit word deur 'n mens gespreek, deur 'n swakke, sondige nietige mens. Netsoos die profeet kan hy ook uitroep; „Wee my, ek is verlore! want ek is ' $n$ man van onrein lippe en woon onder ' $n$ volk wat onrein van lippe is ..." (Jes. 6 vers 5). Maar netsoos hierdie profeet op gloeiende wyse Gods Woord spreek, netso spreek die bedienaar van die goddelike Woord hierdie seëngroet amptelik uit, in die Naam van God, namens God. Maar dan ook weer: Juis die feit dat hy amptelik, namens Hom wat groter is as hy, spreek, sal hom daarvan bewus maak dat hyself nooit die eintlike subjek van hierdie spreke is nie.

b. Die Prediking: Dit is geen blote herhaling van Skrifwoorde nie. Die preek word deur 'n mens gemaak. En tóg kom die prediker nie om sy eie woord en gedagtes te verkondig nie. $\mathrm{Hy}$ is verkondiger van 
die Woord van God. Indien hy dit nie is nie, is hy ook geen verkondiger meer nie.

c. Die Kerksang: Is dit resitatief, dan is dit feitlik woordelike herhaling van Skrifwoorde ........ en tegelykertyd tog weer deur mense gesing, begelei deur die musiek wat deur mense gevorm én uitgevoer word. Is dit in die vorm van 'n hymnus, dan is dit digterlike vryheid verbind met die gebondenheid aan Gods gedagtes en woorde in één eenheid.

d. So-ook met die Skrif-lesing: Dit is Gods Woord wat gelees word. Maar hierdie Gods Woord is altyd tog weer deur mense teboekgestel en vertaal, en word altyd deur mense gehoor.

Ja, elkeen van hierdie momente van die erediens is Gods Woord in een geheel saamverbind. Soos die Tweenatureleer dit i.v.m. Jesus Christus sê, kan ons dit ook op hierdie vlak en gebied oordra en sê : ongeskeie en tog onvermengd.

En tog kan ons (egter sonder om te skei), in hierdie eenheid twee rigtings duidelik onderskei nl. die rigting van die Woord en die rigting van die Antwoord. Die Votum en Seëngroet is Woord omdat die rigting van-God-af deur middel van die amp na-ons-toe is. Dieselfde geld van die Prediking en Skriflesing. D.i. amptelik, van-God-af na-onstoe.

Maar dan is daar ook die rigting van die Antwoord. Die Geloofsbelydenis is die uitspreek van ons belydende antwoord op die openbaring, op die Woord van God. En as antwoord van die hele gemeente, het ons daar geen beswaar teen dat dit ook gesing sal word nie. Die Gebed is ook antwoord. Ons kom tot God met ons lof, dank, smeking. klagte en nood. Die rigting is van-ons-af, na-God-toe. So is dit ook met ons lied-en-musiek. Dit is ons antwoord op die Woord van God Wat na-ons-toe gekom het of, soos ons alreeds in die Ou Testament gesien het: Antwoord in sang, lied en musiek op die groot dade van God.

Maar nou is dit geensins só, dat die Woord-rigting in die erediens alleen Godswoord bevat, en die Antwoord-rigting uitsluitlik uit mensewoord bestaan nie. Ons kan selfs ook nie sê dat die Woordrigting kwantitatief meer Godswoord bevat, en die Antwoordrigting meer mensewoord nie. Dit gaan hier nie om die afmeting van kwantiteite nie, maar om rigting: Van-Bo-af, na-onder-toe én van-ons-af, na-God-toe. En in albei rigtings is Godswoord en mensewoord in één eenheid saamverbind. Die Antwoord gebeur dikwels met woorde wat uit die Heilige Skrif, uit die Woord self ontleen is. Ons noem hier die volgende voorbeelde: 'n Gesangvers wat in die prediking gesiteer word, is verkondiging, is in die rigting van-God-af, na-ons-toe, is Woord. Dieselfde gesangvers in die gemeentelike sang, is van-ons-af, na-God-toe tot Sy eer, 
is Antwoord. 'n Skrifgedeelte in die Skriflesing, is Woord; kom dit egter voor in die gemeentelike sang, dan is dit Antwoord. Dit gaan dus hier om die onderskeiding van twee rigtings in die hele samehang wat ons ,erediens" noem.

Die feit dat Sang en Musiek in die rigting Antwoord lê, . het verskillende konsekwensies. Ons noem alleen die volgende:

(i) Die kerkgebou is die ruimtelike omraming van die erediers, die huis waarin dit woon, die plek waarin dit plaasvind, die vorm waarin dit gestalte aanneem. Maar nou is die struktuur van hierdie ruimtevorm geensins willekeurig nie. Dit het allerlei bindinge bv. met die geskiedenis, die land se boustyl, klimaat, materiaal ens. Maar dit word veral gevorm en bepaal deur die erediens self. Indien bv. die onderdompeling by die doop ' $n$ wesenlike deel van 'n sekere erediens is, dan sal die kerkgebou só ingerig moet word, dat daar op 'n geskikte plek so 'n bad vir onderdompeling van die dopeling ingebou is. Indien die koor in elke erediens optree, dan sal die kerkgebou só gebou mozt word dat daar 'n geskikte ruimte vir 'n sodanige koor bestaan. In die lig van hierdie voorbealde is dit verstaanbaar dat ook die onderskeiding van die Woord - en Antwoordrigting sy invloed op die inrigting en struktuur van die kerkgebou sal hê. Wat die Sang en Musiek in die eredieas betref, raak dit veral die plek van die kerklike musiekinstrument, die orrel, asook (indien daar wel 'n koor is), die plek van die koor binne die kerkgebou. Dit is merkwaardig dat die Woordrigting feitlik uitsluitlik van die kant van die kansel, doopvont en nagmaalstafel kom. Di is dus sinvol dat ons die kerkgebou so sal inrig, dai die Antwoordrigting vanaf die teenoorgestelde kant sal kom omdat dit ant-woord, tzen-woord is. In hierdie sin is dit dus nie korrek wanneer ons die orrel (soos in so baie kerkgeboue in ons land) bokant-agter die kansel inbou nie.

(ii) Die feit dat kerksang en die begeleidende musiek Antwoord is, beteken dat dit nooit Woord d.w.s nooit verkondiging binne die struktuur van die erediens kan wees nie. Kerkmusiek (hetsy as klank. volle agtergrond, hetsy as musiekale verbinding van die genoemde afsonderlike elemente van die erediens, hetsy as begeleiding van die kerksang) is nooit, soos so dikwels gemeen word, evangelieverkondiging in note nie. Die erediens dank nie sy bestaan en die sin van sy bestaan aan die musiek nie, maar omgekeerd: Die musiek is alleen daarom kerkmusiek omdat dit binne die ruimte van die kerk en erediens aan die verkondiging, aan die Woord diensbaar gemaak is. Maar dat dit so is, maak die taak van die kerkmusiek nog geensins klein nie, want wat is skoner as om in lofprysing of smeking ons antwoord aan Hom toe te bring in die mees eksistensiële en tegelyk klankvolste wyse waarop ons as groep, as gemeente dit kan doen? Hier vind die kerkmusiek haar dienende plek. 
Maar is daar géén verkondiging in die musiek nie, en is kerksang dan nie vol van skrifwoorde nie? Sê Ef. 5 vers 19 en 20 dan nie: .,Spreek onder mekaar met psalms en lofsange en geestelike liedere; en sing en psalmsing in julle hart tot eer van die Here, terwyl julle God die Vader altyd vir alles dank in die Naam van onse Here Jesus Christus," en staan daar nie in Kol. 3 vers $16:$; , Leer en vermaan mekaar met psalms en lofsange en geestelike liedere, en sing in julle hart met dankbaarheid tot eer van die Here"? Is hierdie spreek, leer en vermaan dan geen verkondiging, geen prediking nie? Ons wil hieroor die volgende opmerk: Dit is merkwaardig dat Paulus hier oor twee dinge spreek: Eersiens oor die spreek, leer en vermaan van mekaar met psalms, lofsange en geestelike liedere, en tweedens oor die uitsing van ons dankbaarheid tot eer van die Here. Hierdie spreek, leer en vermaan het heel waarskynlik wel in die vorm van sang plaasgevind, maar dan was die intensie daarvan tog nog altyd dat dit wesenlik spreke, wesenlik van die Woordrigting was. Maar dan was dit nie sang en musiek in dié sin waaroor ons in hierdie artikel spreek nie, in die sin (soos Paulus self ook byvoeg) van die uitsing van ons vreugde en dank tot eer van God nie.

Daar kan dus ' $n$ sanguorm bestaan (los van die gehele samehang wat ons hier erediens noem) wat wesenlik Woord is; maar ons handel hier oor die plek van sang en musiek in 'n bepaalde struktuur waar dit nie los staan nie, maar sy besondere sin in 'n bepaalde relasie vind.

Dit mag wel wees dat ons by die aanhoor van 'n bepaalde musiekstuk of lied soms herinner word aan die verkondigde Woord. Dan moet ons egter die volgende twee dinge onthou:

(i) Dat ons daardie lied aanhoor (gewoonlik buite die samehang van die erediens). Indien ons binne die erediens wel saamsing, dan weet ons dat ons nie verkondig nie, maar dat ons loof, prys of smeek, m.a.w. dat ons antwoord.

(ii) Ons moet altyd onthou dat so'n lied of musiekstuk ons herinner aan die verkondigde Woord. Maar dan weet ons ook: Daardie Woord was eerste, daarná eers het die Antwoord (sang en musiek) gekom wat ons daaraan her-inner het. Die verkondiging leef nie van vaagmooie herinneringe nie, maar van die helder klank van die Woord. Die Sokratiese anamnesis en die romantiese herinnering kan gevaarlike kategorieë in die teologie en kerk wees.

3. Daar kan, in hierdie struktuur van Woord-en-Antwoord, ook nog 'n derde vraag na vore tree, $n$ l. die vraag of die erediens met die Woord of met die Antwoord moet begin? 'n Mens verwag redelikerwys dat die erediens met die Woord sal begin - daar kan immers geen Antwoord sonder Woord wees nie. Ons het egter alreeds daarop gewys dat (in die Hervormde Kerk hier te lande) die Voorsang voorafgaan 
aan die Votum en Seëngroet, d.w.s. aan die Woord. Onder die sing van die voorsang kom die predikant en kerkraad dan die kerkgebou binne. Dit is 'n baie ou gebruik, die Introitus (in die ou sin van die woord). Dit is waarskynlik hierdie feit wat Van der Leeuw laat konstateer het: „Een eigenlijk begin hebben de meeste typen van den christelijken eredienst niet." En tog sê Van der Leeuw slegs 'n bladsy verder; ,Terstond na zijn binnenkomst spreekt de Dienaar het Votum ... Het hoort aan het begin of nergens. Alleen het optochtslied kan daaraan eventueel voorafgaan." Creutzberg konstateer egter kategories: "Het Votum is het begin van elke godsdiensoefening. Daarvóór mag niets geschieden, ook geen gemeentezang .....

Ons insiens hoef daar nie noodwendig 'n botsing tussen die Voorsang (wat wel noodsaaklik is, bv, vir die ordelike binnekoms van die predikant en kerkraad) en die Votum bestaan nie. Die erediens begin dan wel met die Votum; die orrelvoorspel en Voorsang is dan alleen voorspel-tot-die-erediens en nog nie die erediens self nie. In hierdie sin sal die spontane aanhef van die voorsang (sonder die aankondiging en voorlees daarvan deur die voorleser) dus die beste vorm wees. In elk geval sal dit nie korrek wees as die voorleser aankondig dat die gemeente die erediens aanvang met die sing van die bepaalde lied nie.

4. Die Woord en die Antwoord staan dus geensins los van mekaar in die eenheid van die erediens nie. Die Antwoord sonder die Prediking, sonder die Woord sal alleen ,'n klinkende metaal of luidende simbaal" wees. Die Prediking, die Woord, aan-die-anderkant sal egter sonder ,die res van die liturgie", sonder die Antwoord (veral van lieden-musiek), 'n stigtelike toespraak voor 'n vereniging wees. Waar die gemeente waarlik gemeente is, daar antwoord sy, daar sing sy en daar is ook kerkmusiek. Die taak van die kerkmusiek is om in hierdie veelvormigheid die eenheid aan te dui, en om tegelykertyd die Woord met die Antwoord te verbind.

Die Prediking, die Woord, behoort helder te wees en duidelik. En tog bly daar nog altyd Gods onpeilbare dieptes, Sy grootheid en verborgenheid oor. Hierdie dinge kan ons nie begryplik sê of rasioneel bereken nie, maar ons kan dit wel aanbid en besing en sodoende heenwys na die diepte en verborgenheid van God.

Maar nou is hierdie lied en musiek nie vrye ontboeseming nie. Dit is in die eerste plek gebonde aan die diens van God. Soos Johannes die Doper is dit 'n stem op die agtergrond wat daardeur die weg van die komende Koning gelyk te maak. Maar daar is ook sekondêre bindinge, bv. die binding aan ' $n$ bepaalde tradisie en styl. Die woorde van 'n lied is bv. ook aan 'n bepaalde taal verbonde. In hierdie opsig is die melodië egter vry. Selfs vreemde volkere kan elkeen in sy eie taal in eenen-dieselfde erediens saam sing en weet dat hulle een en dieselfde Here 
dien. Ons het alreeds oor die eskatologiese karaktertrekke en betekenis van die lied en musiek gepraat; ons kan hier praat van die eukumeniese betekenis daarvan. Dit is die diens, van die sang, maar veral van die kerkmusiek om na hierdie eenheid in Christus Jesus heen te wys. By Babel het die spraak verwar geraak; in Christus kan ons egter weer saamsing. 'n Aartsbiskop van Kantelberg het eenkeer, toe iemand 'n leergeskil i.v.m. die sakramente wou begin, op sy tipies-anglosaksiese en tegelykertyd eukumeniese manier geantwoord: ".Sacraments are for use, not for discussion." Ons kan, met sekere voorbehoude, dieselfde van kerksang en kerkmusiek sê.

Daar bly nog baie teologiese en praktiese aspekte van ons probleem oor, wat ons hier nie behandel en selfs nie eers aangeroer het nie. Dit is goed dat hierdie probleme vandag nie alleen deur teoloë nie, maar deur byna elke gemeentelid van ons Kerk lewendig en selfs bitsig bespreek word. Ons moet egter in ons bespreking oppas, dat ons nie (soos alte dikwels gebeur) allerlei on-teologiese argumente gebruik soos bv. "waar ek grootgeword het," of „, in ons gemeente word só en so gedoen . . . en daarom is dit reg." Ons moet veral ook daarvoor op ons hoede wees, dat ons nie allerlei wetjies van "mag" en "mag nie" gaan oplê nie, veral nie wat lied en musiek in die erediens aanbetref nie. Dan sal ons met die valbyl van die wet, van ons wet, hierdie skone, eksistensiële, klankvolle, vrye en vreugdevolle vorm van Sy diens smoor en doodmaak. Laat ons onthou dat die Evangelie in die Wet nêrens so duidelik na vore tree as wanneer die Wet gesing word nie.

Universiteit van Pretoria.

B. J. ENGELBRECHT. 